\title{
Nicotinic Acid Receptor GPR109A Is Down-Regulated in Human Macrophage-Derived Foam Cells
}

\author{
Joshua T. Chai ${ }^{1}$, Janet E. Digby ${ }^{1}$, Neil Ruparelia ${ }^{1}$, Andrew Jefferson ${ }^{1}$, Ashok Handa ${ }^{2}$, \\ Robin P. Choudhury ${ }^{*}$ *
}

1 Division of Cardiovascular Medicine, University of Oxford, Oxford, United Kingdom, 2 Nuffield Department of Surgical Sciences, University of Oxford, Oxford, United Kingdom

\begin{abstract}
Nicotinic acid (NA) regresses atherosclerosis in human imaging studies and reduces atherosclerosis in mice, mediated by myeloid cells, independent of lipoproteins. Since GPR109A is expressed by human monocytes, we hypothesized that NA may drive cholesterol efflux from foam cells. In THP-1 cells NA suppressed LPS-induced mRNA transcription of MCP-1 by 76.6 $\pm 12.2 \%(P<0.01)$ and TNF $\alpha$ by $56.1 \pm 11.5 \%(P<0.01)$, yet restored LPS-induced suppression of PPAR $\gamma$ transcription by $536.5 \pm 46.4 \%(P<0.001)$ and its downstream effector $C D 36$ by $116.8 \pm 19.8 \%(P<0.01)$. Whilst direct PPAR $\gamma$-agonism promoted cholesterol efflux from THP-1 derived foam cells by $37.7 \pm 3.1 \%(P<0.01)$ and stimulated transcription of $L X R \alpha$ by 87.9 $\pm 9.5 \%(P<0.001)$ and $A B C G 1$ by $101.2 \pm 15.5 \%(P<0.01)$, NA showed no effect in foam cells on either cholesterol efflux or key RCT genes transcription. Upon foam cell induction, NA lost its effect on PPAR $\gamma$ and cAMP pathways, since its receptor, GPR109A, was down-regulated by foam cell transformation. This observation was confirmed in explanted human carotid plaques. In conclusion, despite NA's anti-inflammatory effect on human macrophages, it has no effect on foam cells in reverse cholesterol transport; due to GPR109A down-regulation.
\end{abstract}

Citation: Chai JT, Digby JE, Ruparelia N, Jefferson A, Handa A, et al. (2013) Nicotinic Acid Receptor GPR109A Is Down-Regulated in Human Macrophage-Derived Foam Cells. PLoS ONE 8(5): e62934. doi:10.1371/journal.pone.0062934

Editor: Andrea Cignarella, University of Padova, Italy

Received January 31, 2013; Accepted March 27, 2013; Published May 2, 2013

Copyright: (C) 2013 Chai et al. This is an open-access article distributed under the terms of the Creative Commons Attribution License, which permits unrestricted use, distribution, and reproduction in any medium, provided the original author and source are credited.

Funding: The authors' laboratory is supported by the British Heart Foundation; RPC is a Wellcome Trust Senior Research Fellow in Clinical Science; JTC is an MRC Clinical Research Training Fellow; the funders had no role in study design, data collection and analysis, decision to publish, or preparation of the manuscript.

Competing Interests: The authors have read the journal's policy and have the following conflicts to declare: RPC has received travel/research support and served as a member on the advisory board of Roche and Merck/MSD.

*E-mail: robin.choudhury@cardiov.ox.ac.uk

\section{Introduction}

For over fifty years, nicotinic acid (NA) has been known to exert favourable effects on plasma lipoproteins [1]. It reduces atherogenic lipoproteins LDL-c, VLDL-c, and $\operatorname{Lp}(\mathrm{a})$, and is the most efficacious drug currently available to raise plasma HDL-c (by up to $30 \%$ ) [2]. The Coronary Drug Project [3] has shown benefits of NA in reducing cardiovascular events and mortality in patients with coronary heart disease, a finding supported by 2 recent metaanalyses [4,5]. Furthermore, numerous trials have shown that NA reduces atherosclerosis, estimated from coronary angiography [6,7]; carotid ultrasound [8-11] and MRI [12]. However, one recent outcome trial was abandoned due to lack of efficacy [13]. A larger Phase III trial of a niacin/laropiprant combination also did not reach its primary end point [14].

In addition to the recognized effects on plasma lipoproteins, it has emerged that NA has a variety of additional actions that are of potential relevance to processes of atherosclerosis progression and regression. In adipocytes [15] and certain non-foam cell 'basalstate' mononuclear cell lines [16,17], NA activates the reverse cholesterol transport apparatus, namely $\operatorname{PPAR} \gamma, \operatorname{LXR} \alpha$, and the $\mathrm{ABC}$ transporter proteins, which are known to be responsible for in vitro cholesterol unloading [18] and, in turn, are directly implicated in the regression of experimental atherosclerosis $[19,20]$. These observations raise the possibility that effects of NA on atherosclerotic plaque regression and cardiovascular risk reduction may, in part, be due to direct effects on foam cell cholesterol unloading.

GPR 109A (also known as hydroxy-carboxylic acid 2 receptor or HM74a) which is the receptor for nicotinic acid, has been shown to mediate an expanding repertoire of potentially therapeutic actions $[21,22]$. This receptor belongs to a family of Gi-proteincoupled cell surface receptors that are expressed in adipocytes and immune cells in both human and rodent species [21]. We have recently reported potent anti-inflammatory effects of NA in both human adipocytes [23] and monocytes [24], which are mediated via GPR109A-dependent mechanisms. The relevance of these observations has been enhanced by a recent study in mice, which has shown that NA reduces progression of atherosclerosis, via GPR109A on myeloid cells, without affecting plasma lipoproteins [25].

The observations that, NA (i) plays a role in atherosclerosis regression in humans and (ii) has the capacity to act directly on monocyte/macrophage function by up-regulating proteins that are involved in cellular cholesterol efflux, raise the important possibility that NA may exert effects, via its receptor GPR109A, in foam cells to induce cholesterol efflux, leading to plaque regression. Accordingly, we sought to test the effects of NA on human macrophage-derived foam cells and explore its cellular mechanisms of action in the context of lipid handling and atherogenesis. 


\section{Methods}

\section{Cell Culture and Treatment}

THP-1 cells were purchased from American Type Culture Collection (ATCG, Teddington, UK) and maintained in RPMI 1640 medium (Sigma-Aldrich, Poole, UK) until treatment, at a density between $4-8 \times 10^{5}$ cells $/ \mathrm{mL}$, supplemented with fetal bovine serum (10\%, Invitrogen, Paisley, UK) and 2-mercaptoethanol (0.05 mM, Sigma-Aldrich, Poole, UK), in a humidified atmosphere of $95 \%$ air $/ 5 \% \mathrm{CO}_{2}$ at $37^{\circ} \mathrm{C}$. Cells were treated with nicotinic acid (Sigma-Aldrich, Poole, UK) at $1 \times 10^{-3}$ to $10^{-6} \mathrm{M}$ or PPAR $\gamma$ agonist GW1929 $\left(2 \times 10^{-6} \mathrm{M}\right.$, Tocris Bioscience, Bristol, UK) versus vehicle-only controls.

\section{In vitro Cholesterol Loading and Efflux}

THP-1 monocytic cells were seeded in 96-well or 6-well plates at $1 \times 10^{6}$ cells $/ \mathrm{mL}$ density and allowed to differentiate for 48 hours into basal macrophages, in the presence of $50 \mathrm{ng} / \mathrm{mL}$ phorbol myristate acetate (PMA). For cholesterol loading and foam cell induction, basal macrophages were washed once with warm PBS and serum-starved for 12 hours, followed by incubation with acetylated $(\mathrm{ac}-)$ LDL $(50 \mu \mathrm{g} / \mathrm{mL}$, Biomedical Technologies, Inc, USA) for 48 hours (Figure $\mathrm{S} 1$ shows cell treatment regime in diagrammatic details). Foam cell formation was confirmed by Oilred-O (Sigma-Aldrich, Poole, UK) staining in sample wells. Cholesterol efflux was assessed using HDL3 $(50 \mu \mathrm{g} / \mathrm{mL}$, Meridian Life Science, USA) and apolipoprotein (Apo) AI $(10 \mu \mathrm{g} / \mathrm{mL}$, Sigma-Aldrich, Poole, UK) as cholesterol acceptors and a nonradioactive enzymatic method (Amplex Red Cholesterol Assay kit, Invitrogen, Paisley, UK) modified from Robinet, et al. [26]. In brief, after the indicated treatment period, cell culture supernatants were collected and stored for later analysis; while foam cells were washed in cold PBS twice and cellular cholesterol extracted by incubation with hexane:isopropanol (3:2) solvent mixture with gentle agitation for 30 minutes. This solvent mixture was then transferred to $1.5 \mathrm{~mL}$ Eppendorf microtubes for suction evaporation with the dried cholesterol residue reconstituted in an enzyme-compatible solvent system isopropanol:Nonidat P40 (9:1, Roche, Burgess Hill, UK), supplemented with $20 \mathrm{U} / \mathrm{mL}$ of bovine catalase (Sigma-Aldrich, Poole, UK) to quench intrinsic peroxide activity. Extracted cellular and supernatant cholesterol content was then determined using Amplex Red Cholesterol Assay kit (Invitrogen, Paisley, UK) as per manufacturer's instruction.

\section{mRNA Extraction and Quantitative Real-time RT-PCR}

Total RNA was prepared using Qiagen ${ }^{\circledR}$ (Crawley, UK) RNEasy mini columns and $1 \mu \mathrm{g}$ was reverse transcribed using a QuantiTect ${ }^{\circledR}$ Reverse Transcription Kit with Oligo dTs and random hexamers as primers. Real-time PCR was carried out with $1 \mu \mathrm{L}$ of cDNA in a $10 \mu \mathrm{L}$ reaction mix using custom primers with SYBR Green PCR master mix, or with Taqman ${ }^{\mathrm{TM}}$ Gene Expression assays (Applied Biosystems, Warrington, UK). Quantification was performed by the $-\Delta \Delta \mathrm{CT}$ method [27], normalized to the housekeeping gene cyclophilin. Custom designed primers $\left(5^{\prime}\right.$ - to $\left.3^{\prime}-\right)$ for PPAR $\gamma$ forward GATTTCACTATGGAGTTCATGGTTGT, reverse CATCTGTCATAGATAAGCTTCAATCTGA; NR1H3 (for LXR $\alpha$ ) forward AAGCGCTGCATGCGTAGGT, reverse GCATCGGTGGGAACATCAG; ABCA1 forward GACAAATAAAAT-CAAGGATGGGTACTG, reverse AGACGTACGGCATGTCGTCAA; ABCG1 forward TGTCGGCACATCTGAAGCTT, reverse TGTCAGTATCTCGTTGA-CGATTTCG; GPR109A forward GCGTTGGGACTGGAAGTTTG, reverse GCGGTTCATAGCGAACATGA. Taqman ${ }^{\mathrm{TM}}$ Gene Expression assay primers from Applied Biosystems, Warrington, UK, were used for TNF $\alpha$ (Hs00174128_ml), MCP-1 (Hs00234140_ml), and CD36 (Hs00169627_ml).

\section{PPAR Transcription Factor Binding Assay}

After treatment, THP-1 basal macrophages and foam cells were washed and total nuclear protein lysates prepared using Nuclear Extraction Kit (Millipore, Watford, UK). Nuclear protein contents were quantified by BCA assay (Thermo Scientific, Hemel Hempstead, $\mathrm{UK}$ ) and $3 \mu \mathrm{g}$ of total nuclear protein per sample was used to evaluate PPAR transcription factor binding activity using $\operatorname{PPAR} \alpha, \delta$, $\gamma$ Complete Transcription Factor Assay Kit (Cayman Chemical, Michigan, USA) as per manufacturer's instruction.

\section{Cyclic-AMP Assay}

To determine the optimal treatment time period, basal macrophages were first incubated with $\mathrm{NA}$ at $1 \times 10^{-4} \mathrm{M}$ with duration ranging from 0 to 24 hours. Cellular cAMP concentration was determined using the Parameter ${ }^{\text {TM }}$ Cyclic AMP ELISA kit ( $R \&$ D Systems, Abingdon, UK). To evaluate $G_{i / o}$-protein involvement, cells were pre-incubated with pertussis toxin (100 ng/mL, Calbiochem, Merck, Nottingham, UK) versus vehicle for 18 hours, prior to treatment with NA for the optimal time period determined previously.

\section{Western Blot}

Cells in culture dish were harvested and lysed with CelLytic ${ }^{\text {TM }}$ cell lysis reagent (Sigma-Aldrich, Poole, UK) with Complete ${ }^{\text {TM }}$ protease inhibitor cocktail (Roche, Burgess Hill, UK) before total cell lysate protein quantification by BCA assay (Thermo Scientific, Hemel Hempstead, UK). $12 \mu \mathrm{g}$ of total lysate protein were denatured and loaded in NuPage gel (Invitrogen, Paisley, UK) for electrophoresis. Protein bands were transferred to membrane using iBlot dry transfer system (Invitrogen, Paisley, UK), and probed with rabbit anti-human GPR109A (1:1000, Imgenex, USA) primary antibody in PBS-Tween $+5 \%$ BSA at $4^{\circ} \mathrm{C}$ overnight. After three washes, the membrane was incubated with anti-rabbit IgG HRP secondary antibody (1:2000, GE Healthcare, Amersham, UK) at room temperature for 1 hour. Antibody complexes were visualised using ECL advanced detection kit (GE Healthcare, Amersham, UK). Loading control was performed using antibody against $\beta$-tubulin.

\section{Ex-vivo Human Carotid Atherosclerotic Plaque}

Carotid atherosclerotic plaque samples were obtained from patients undergoing carotid endarterectomy in routine clinical care at Oxford University Hospital, with full written informed consent. Ethics approval was obtained from National Research Ethics Services (NRES) and local R\&D committee prior to the beginning of the study and conformed to the Declaration of Helsinki. At the time of carotid endarterectomy, plaque samples were freshly divided. A small part of each plaque was formalin fixed, processed, and paraffin embedded (FFPE) for Masson's trichrome staining for plaque morphology; while the remaining segments of the plaque were snap-frozen in OCT. Paraffin sections $(5 \mu \mathrm{m})$ and frozen sections $(10 \mu \mathrm{m})$ were obtained for histological and immunohistochemistry staining. Oil-red-O (Sigma-Aldrich, Poole, UK) staining was performed in selected co-staining experiments.

\section{Fluorescence Immunocytochemistry}

Cultured cells or air-dried cryosections were fixed in ice-cold acetone for 10 minutes, washed with PBS, and blocked with serum-free protein blocking solution (Dako, Cambridge, UK) for 2 
hours in room temperature. They were then incubated with mouse anti-human CD68 antibodies (1:300, Dako, Cambridge, UK), rabbit anti-human GPR109A antibodies (1:200, Imgenex, USA), and goat anti-human adipophilin antibodies (1:100, Santa Cruz Biotechnology, Santa Cruz, CA, USA) at $4^{\circ} \mathrm{C}$ overnight. After washing, cells/cryosections were incubated with donkey antimouse IgG Alexa Fluor 647, (Invitrogen, Paisley, UK), donkey anti-rabbit IgG Alexa Fluor 594 (Invitrogen, Paisley, UK), and donkey anti-goat IgG Alexa Fluor 488 (Invitrogen, Paisley, UK) secondary antibodies at room temperature for 1 hour. After DAPI/TO-PRO3 nuclear counterstain, images were taken using a Leica DM2500 microscope with QImaging MicroPublisher 5.0 RTV image sensor, and a Leica SP-5 laser-scanning confocal microscope. To ensure adipophilin antibody binding specificity, competitive peptide blocking experiment was performed with the peptide from Santa Cruz Biotechnology used to raise its antiadipophilin antibody. In lipid co-staining experiments, the immediately adjacent cryosection was fixed in 4\% PFA for 1 hour, and stained with $36 \%$ solution of Oil-red-O (ORO) in triethyl phosphate (Sigma-Aldrich, Poole, UK) for 30 minutes. ORO staining was detected using Texas Red excitation filter $(540-580 \mathrm{~nm})$ in epifluorescence.

\section{Statistical Methods}

Values are expressed as mean \pm SEM for replicates between experiments. Data were analyzed using Student's t-tests with significance set at $\mathrm{P}<0.05$. Statistical software packages used for analysis include GraphPad Prism 5 and IBM SPSS Statistics v19.

\section{Results}

\section{NA Suppresses LPS-induced Transcription of Pro- inflammatory Mediators}

We first established the response to NA in basal state (i.e. nonfoam cell) macrophages. The TLR-4 agonist lipopolysaccharide (LPS) was used as an inflammatory stimulus. THP-1 macrophages were incubated with LPS $(50 \mathrm{ng} / \mathrm{mL})$ for 18 hours, followed by $1 \times 10^{-4} \mathrm{M}$ NA for 24 hours. Previous dose-response experiments $\left(1 \times 10^{-3}\right.$ to $\left.10^{-6} \mathrm{M}\right)$ established optimal dosing of NA and excluded detrimental effects on cell viability [24]. Pre-incubation with LPS increased mRNA transcription of pro-inflammatory cytokines: MCP-1 by 80 -fold $(\mathrm{P}<0.001, \mathrm{n}=3$ per group); and $\mathrm{TNF} \alpha$ by 10 -fold $(\mathrm{P}<0.001, \mathrm{n}=3$ per group) (Figure $1 \mathrm{~A})$. As we have previously reported, NA treatment significantly attenuated this LPS-induced transcriptional up-regulation by $76.6 \pm 12.2 \%$ for MCP-1 ( $\mathrm{P}<0.01, \mathrm{n}=3$ per group), and by $56.1 \pm 11.5 \%$ for $\mathrm{TNF} \alpha$ $(\mathrm{P}<0.01, \mathrm{n}=3$ per group), confirming the anti-inflammatory effect of NA on basal non-foam cell macrophages.

\section{NA Restores LPS-induced Transcriptional Suppression of PPAR $\gamma$ in Basal Macrophages}

$\operatorname{PPAR} \gamma$ contributes to the regulation of reverse cholesterol transport apparatus and cellular lipid metabolism. We first established that pre-incubation with LPS suppressed PPAR $\gamma$ and its downstream effector CD36 mRNA transcription by $90 \%$ $(\mathrm{P}<0.001, \mathrm{n}=3$ per group) and $83 \%(\mathrm{P}<0.001, \mathrm{n}=3$ per group $)$, respectively (Figure 1B). This LPS-induced transcriptional suppression was effectively reversed by treatment with NA, which increased PPAR $\gamma$ by $536.5 \pm 46.4 \%(\mathrm{P}<0.001, \mathrm{n}=3$ per group $)$ and CD36 by $116.8 \pm 19.8 \%(\mathrm{P}<0.01, \mathrm{n}=3$ per group $)$.

\section{GW1929 but not NA Promotes Cholesterol Efflux from Macrophage-derived Foam Cells}

Activation of PPAR $\gamma$ facilitates reverse cholesterol transport (RCT) by up-regulation of $\mathrm{ABC}$ transporter proteins via recruitment and dimerization of another nuclear transcription factor, $\operatorname{LXR} \alpha$ [28]. Since NA activated PPAR $\gamma$ in basal macrophages, we hypothesized that NA might promote RCT in macrophage-derived foam cells. Basal macrophages were induced into foam cells, confirmed by Oil-red-O staining in sample wells (Figure 2A). Foam cells were treated with NA, GW1929 or vehicles only for 4, 24, or 48 hours, followed by cholesterol efflux for 24 hours facilitated by cholesterol acceptor HDL3 or ApoAI in the culture medium. As anticipated, direct activation of PPAR $\gamma$ by GW1929 resulted in significantly higher cholesterol efflux as demonstrated by a reduction in extracted cellular cholesterol by $37.7 \pm 3.1 \%$ in GW1929+ HDL group compared to incubation with HDL alone $(\mathrm{P}<0.01, \mathrm{n}=2$ per group); and by $15.6 \pm 4.3 \%$ in GW1929+ ApoAI group compared to incubation with ApoAI alone $(\mathrm{P}<0.05, \mathrm{n}=2$ per group) (Figure 2B). Corresponding cholesterol contents in efflux supernatants were increased by $15.8 \pm 2.7 \%$ in GW1929+ HDL group ( $\mathrm{P}<0.05, \mathrm{n}=2$ per group); though no significant change was detected in the GW1929+ ApoAI group. Nicotinic acid treatment had no effect on either extracted cellular cholesterol or supernatant cholesterol content at a range of NA concentration $1 \times 10^{-3}$ to $10^{-6} \mathrm{M}$ compared to either HDL or ApoAI alone groups. (Representative data at $1 \times 10^{-4} \mathrm{M}$ NA concentration of 24 hours treatment shown in Figure 2B; no difference was detected in 3 repeat experiments, each with $n=4$ per group. Data from other time points shown in Figure S2).

\section{Effect of NA and GW1929 on Reverse Cholesterol Transport Apparatus: $\mathrm{LXR} \alpha, \mathrm{ABCA} 1$ and $\mathrm{ABCG} 1$}

In order to elucidate why NA had no effect on RCT in foam cells, we investigated the effect of NA and GW1929 on genes in the PPAR $\gamma$-LXR $\alpha$-ABC transporters pathway. We first confirmed that PPAR $\gamma, \mathrm{NR} 1 \mathrm{H} 3$ (for LXR $\alpha$ ), and ABCAl were indeed all lipid sensitive genes using qRT-PCR. mRNA transcription of all three genes were significantly up-regulated by cholesterol loading. Immediately following 48 hours of $50 \mu \mathrm{g} / \mathrm{mL}$ ac-LDL incubation, PPAR $\gamma$ mRNA transcript was significantly increased by 4.3 -fold $(\mathrm{P}<0.001)$; NR1H3 by 3.6-fold $(\mathrm{P}<0.001)$; and ABCA1 by 4.7 fold $(\mathrm{P}<0.01)$ (Figure $3 \mathrm{~A})$. However, after resting these induced foam cells in standard media (RPMI supplemented with $10 \%$ fetal bovine serum and $0.05 \mathrm{mM}$ 2-mercaptoethanol) for 24 hours after induction, the mRNA transcript levels of all 3 genes returned to baseline or below-baseline levels. This time point was adopted for subsequent experiments given the intention to test the potential for gene up-regulation upon treatment. Basal macrophages and foam cells were treated with $1 \times 10^{-4} \mathrm{M} \mathrm{NA}$ or $2 \times 10^{-6} \mathrm{M}$ GW1929 versus vehicles for 4 or 24 hours. In basal macrophages, NA significantly up-regulated ABCG1 mRNA transcription at 24 hours by $92.1 \pm 11.8 \%(\mathrm{P}<0.001, \mathrm{n}=3$ per group $)$. In foam cells, however, NA showed no effect on transcriptional regulation (Figure 3B). This contrasts with direct $\operatorname{PPAR} \gamma$ activation using GW1929, where significant transcriptional activation was seen with both NR1H3 and ABCG1 in both basal macrophages and foam cells at 4 hours and 24 hours.

\section{PPAR $\gamma$ Pathway is Activated by NA in Basal Macrophages but not in Foam Cells}

In view of the discrepancy of $\mathrm{ABC}$ transporters activation between GW1929 and NA treatment, we sought to explore 
A

MCP-1 mRNA

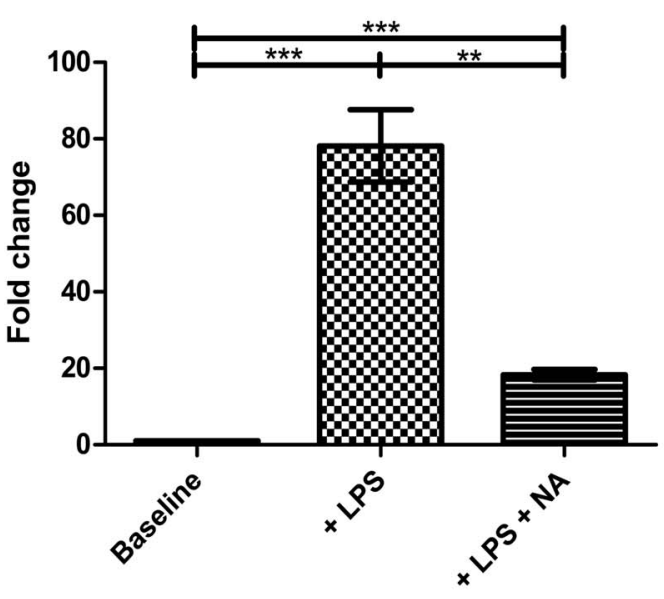

TNF $\alpha$ mRNA

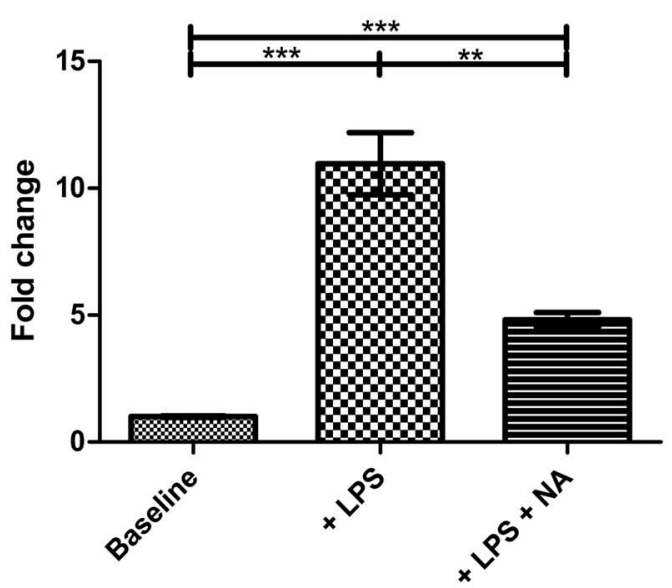

B PPAR $\gamma$ mRNA

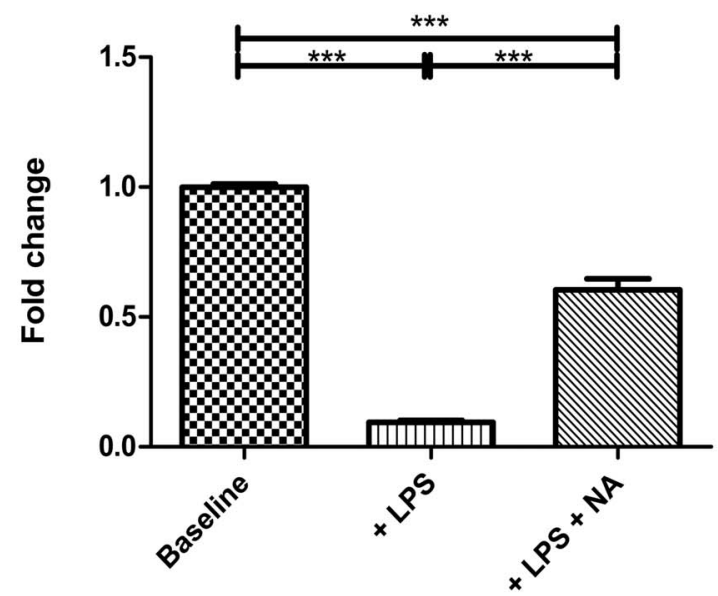

CD36 mRNA

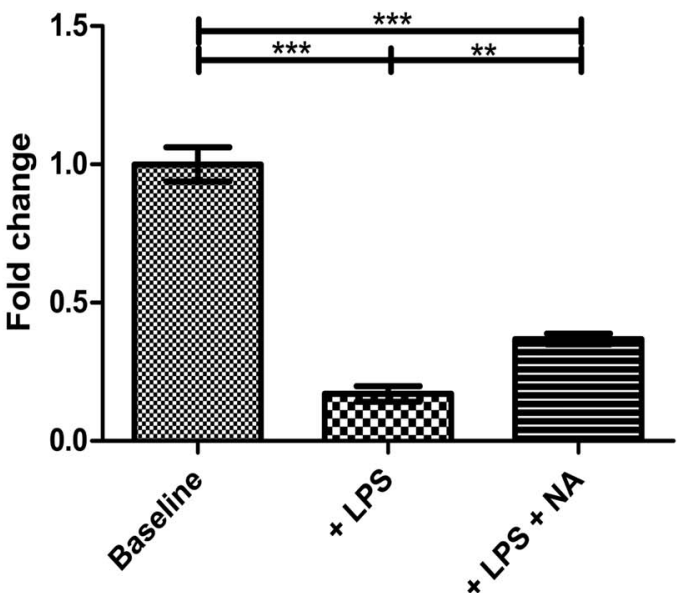

Figure 1. Effects of nicotinic acid (NA) on mRNA transcription of MCP-1, TNF $\alpha$, PPAR $\gamma$, and CD36. Basal THP-1 macrophages were preincubated with LPS prior to administration of NA versus vehicle controls. 1A LPS increased mRNA transcription of MCP-1 and TNF $\alpha$, while NA treatment attenuated this LPS-induced up-regulation ( $n=3$ per group). 1B LPS suppressed mRNA transcription of PPAR $\gamma$ and its downstream effector CD36, yet treatment by NA effectively reversed it ( $n=3$ per group). ${ }^{*} \mathrm{P}<0.05,{ }^{*} \mathrm{P}<0.01,{ }^{* * *} \mathrm{P}<0.001$, ns $=$ non significant.

doi:10.1371/journal.pone.0062934.g001

putative cellular mechanisms by which ABCAl and ABCG1 may be regulated by NA. Having already established that NA could reverse LPS-induced suppression of PPAR $\gamma$ and CD36 mRNA transcription in basal THP-1 macrophages, we tested, in the absence of LPS, direct $\operatorname{PPAR} \alpha, \delta, \gamma$ transcription factor binding activity (TFBA) activated by $1 \times 10^{-4} \mathrm{M}$ NA in basal macrophages and foam cells using ELISA. PPAR $\alpha$ TFBA was significantly increased in foam cells compared to basal macrophages by $36.3 \pm 6.2 \%(\mathrm{P}<0.001, \mathrm{n}=6$ per group $)$, whereas PPAR $\delta$ and PPAR $\gamma$ TFBA were both significantly diminished in foam cells compared to basal macrophages by $25.8 \pm 3.6 \% \quad(\mathrm{P}<0.001$, $\mathrm{n}=6$ per group), and $26.9 \pm 5.1 \%(\mathrm{P}<0.001, \mathrm{n}=6$ per group $)$, respectively. Interestingly, NA significantly increased PPAR $\gamma$ TFBA in basal macrophages by $20.8 \pm 4.5 \%(\mathrm{P}<0.01, \mathrm{n}=3$ per group) (Figure 4A). This PPAR $\gamma$ activation in basal non-LPS stimulated macrophages by NA was further confirmed by quantitative RT-PCR showing up-regulation of PPAR $\gamma$ downstream effector $\mathrm{CD} 36$ by $73.7 \pm 12.6 \%(\mathrm{P}<0.01, \mathrm{n}=3$ per group). In contrast, no effect on PPAR $\gamma$ TFBA or CD36 mRNA transcription was seen in foam cells.
Cyclic AMP is Suppressed by NA in Basal Macrophages, but not in Foam Cells

Another potential mechanism for NA-induced activation of ABC transporters is via G-protein mediated cyclic AMP regulation [29]. NA activates GPR109A, a $\mathrm{G}_{\mathrm{i}}$-protein coupled receptor, and reduces cAMP in adipocytes [30]. We found cAMP level in basal THP-1 macrophages dropped within 5 minutes after the application of $1 \times 10^{-4} \mathrm{M}$ NA and this reduction persisted for at least 24 hours (Figure 4B). We then pre-incubated basal macrophages and foam cells with $100 \mathrm{ng} / \mathrm{mL}$ pertussis toxin (PTX, to inhibit $\mathrm{G}_{\mathrm{i} / \mathrm{o}}$ coupling) or vehicle-only for 18 hours followed by $1 \times 10^{-4} \mathrm{M}$ NA for 1 hour. In basal macrophages, cAMP level was significantly diminished in NA alone group compared to control by $41.5 \pm 14.8 \%(\mathrm{P}<0.05, \mathrm{n}=3$ per group $)$ and this effect was abolished by PTX pre-incubation, confirming the role of $\mathrm{G}_{\mathrm{i} / \mathrm{o}}$-protein signaling involved in NA activation (Figure 4C). In contrast, NA did not affect cAMP level in foam cells (Figure 4D). 

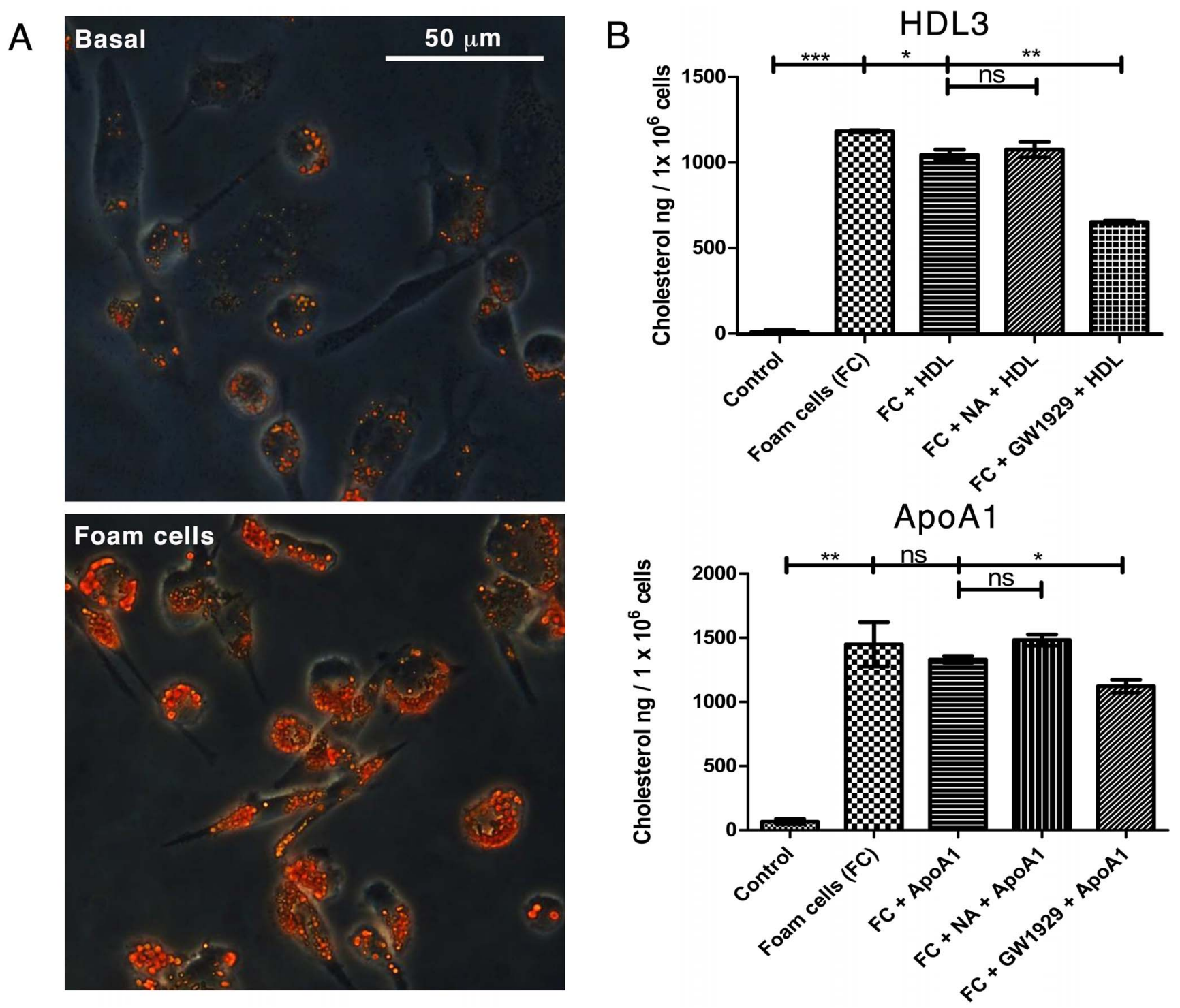

Figure 2. Foam cell induction and the effects of NA and GW1929 on foam cell cholesterol efflux. 2A Phase-contrast microscopy of Oilred-O staining of THP-1 cells in basal (upper) and foam cells (lower) states, confirming foam cell induction. 2B Foam cells were treated with NA, GW1929, or vehicles only for 24 hours, followed by cholesterol efflux facilitated by HDL3 or ApoAl in the culture medium. Cholesterol efflux was studied by measuring cellular cholesterol content after hexane:isopropanol extraction. GW1929 treatment reduced extracted cellular cholesterol in GW1929+ HDL group versus with HDL alone; and in GW1929+ ApoAl group versus with ApoAl alone ( $n=2$ per group). NA treatment had no effect on extracted cellular cholesterol content at a range of NA concentration $1 \times 10^{-3}$ to $10^{-6} \mathrm{M}$ compared to either HDL3 or ApoAl alone groups. (Representative data at $1 \times 10^{-4}$ M NA concentration shown). ${ }^{*} \mathrm{P}<0.05$, ${ }^{* * \mathrm{P}}<0.01,{ }^{* * *} \mathrm{P}<0.001, \mathrm{~ns}=$ non significant. doi:10.1371/journal.pone.0062934.g002

\section{GPR109A Expression is Lost in Foam Cells in vitro}

Since neither cAMP nor PPAR $\gamma$ pathways were influenced by NA in foam cells, we examined the expression pattern of GPR109A in cell culture. Using quantitative real-time RT-PCR, we showed that GPR109A mRNA was not expressed in undifferentiated THP-1 cells but expression was seen after differentiation into basal macrophages (Figure 5A). Treatment with NA for 24 hours, as expected with G-protein coupled signaling, caused desensitization and significant down-regulation of GPR109A mRNA transcription by $70 \pm 16.9 \%(\mathrm{P}<0.01, \mathrm{n}=3$ per group $)$. Surprisingly, foam cell induction alone caused an even more dramatic down-regulation of GPR109A mRNA transcription by $87 \pm 17 \%$ compared to basal macrophages $(\mathrm{P}<0.01, \mathrm{n}=3$ per group). To confirm this finding at a protein level, we performed
Western blot and fluorescence immunocytochemistry on basal macrophages and foam cells. Figure 5B showed the loss of protein expression of GPR109A in total cell lysates from foam cells compared to basal macrophages in a Western blot; whereas Figure 5C and 5D demonstrated the expression of GPR109A on the cell surface in cultured THP-1 basal macrophages (5C), and the down-regulation of GPR109A expression after foam cell induction $(5 \mathrm{D})$.

GPR109A is Expressed in Human Carotid Plaques but its Expression is Down-Regulated in Carotid Plaque Foam Cells

Finally, to ascertain whether these in-vitro findings are of potential clinical significance, we analysed human carotid athero- 
A

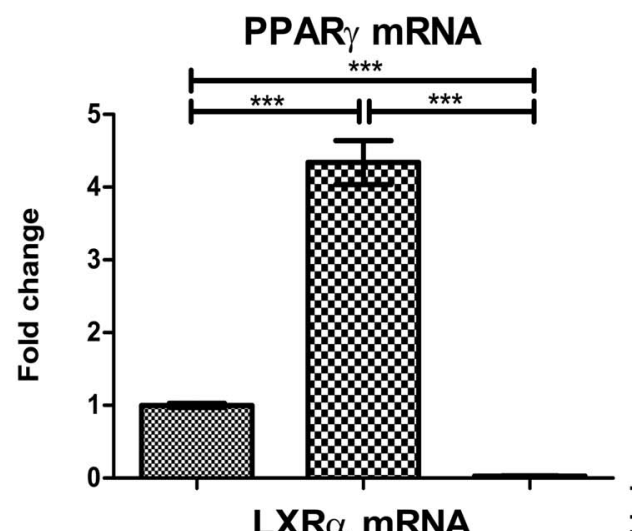

B
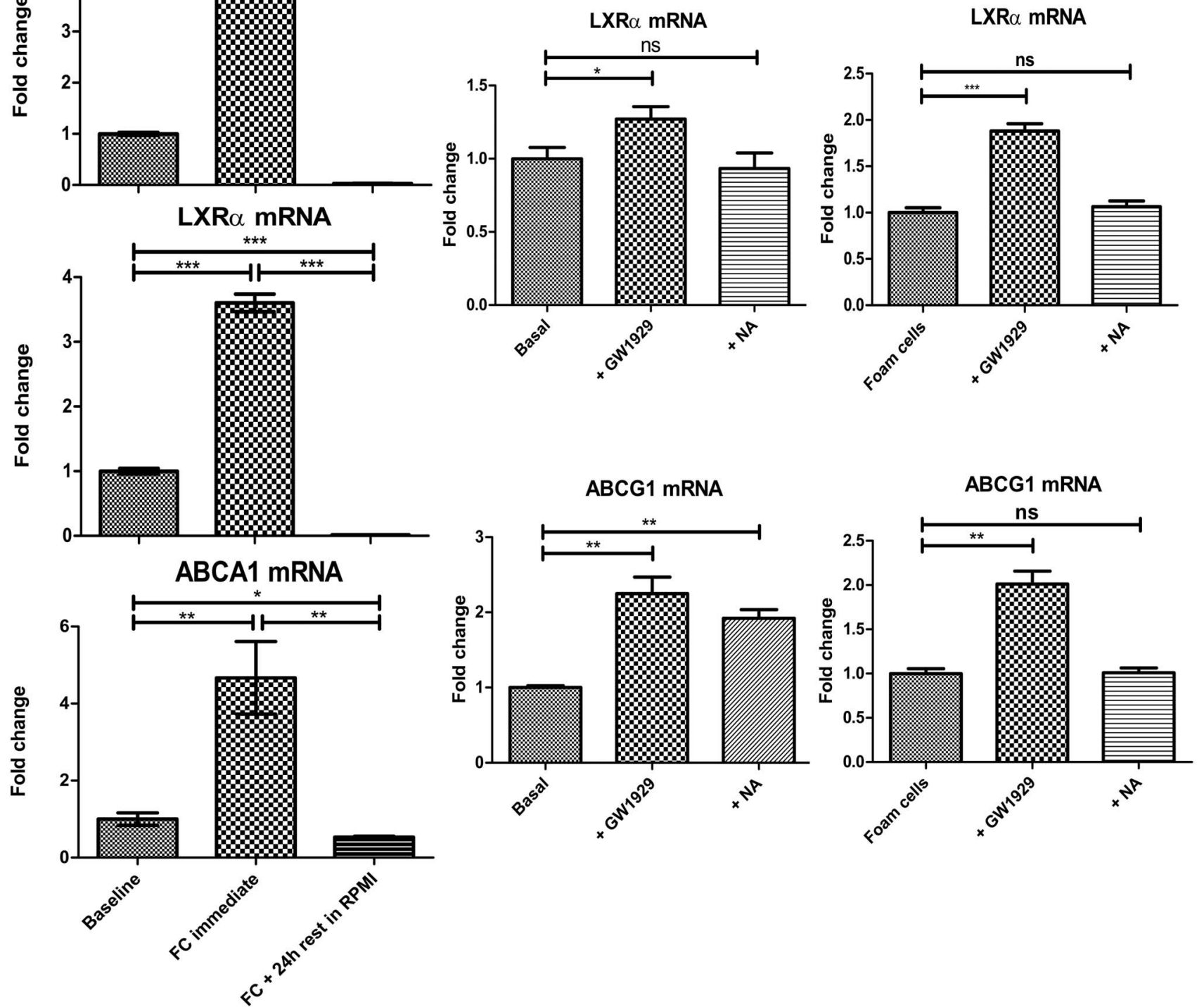

Figure 3. Effects of NA and GW1929 on reverse cholesterol transport apparatus: LXRa, ABCA1 and ABCG1. 3A mRNA transcription of all three genes were significantly up-regulated immediately following cholesterol loading but returned to baseline or below-baseline level after resting in standard RPMI media for 24 hours. 3B In basal macrophages, NA significantly up-regulated ABCG1 mRNA transcription ( $n=3$ per group); this effect was not seen in foam cells. PPAR $\gamma$ activation using GW1929 significantly up-regulated mRNA transcription with both NR1H3 and ABCG1 in both basal macrophages and foam cells. ${ }^{*} \mathrm{P}<0.05$, ${ }^{* *} \mathrm{P}<0.01$, ${ }^{* *} \mathrm{P}<0.001$, ns $=$ non significant

doi:10.1371/journal.pone.0062934.g003

sclerotic plaques from endarterectomy. Five recently symptomatic carotid plaques were obtained for histological and fluorescence immunohistochemistry. At the region of maximal luminal stenosis, $10 \mu \mathrm{m}$ cryosections were double-stained with antibodies against CD68 and GPR109A; with the immediately adjacent section stained with Oil-red-O to visualise plaque lipid distribution. As shown in Figure 6A, CD68-positive cells were consistently observed clustering at the interface between the lipid-rich area and the overlying fibrous cap layer; and a sub-population of these CD68-positive cells also expressed GPR109A. More importantly,
GPR109A co-expression was observed in CD68-positive cells outside of the lipid-rich area, whereas CD68-positive cells within the lipid-rich area, which are highly likely to represent macrophage-derived foam cells, do not co-express GPR 109A. Figure 6B and $6 \mathrm{C}$ showed confocal images of the co-expression of GPR109A and CD68 in basal macrophages outside of lipid core (6B), and the markedly diminished GPR109A co-expression in CD68-positive macrophages inside the lipid-rich area $(6 \mathrm{C})$. To further confirm our finding, we performed co-localisation experiment using antibodies against CD68, GPR109A, and a lipid-droplets associ- 

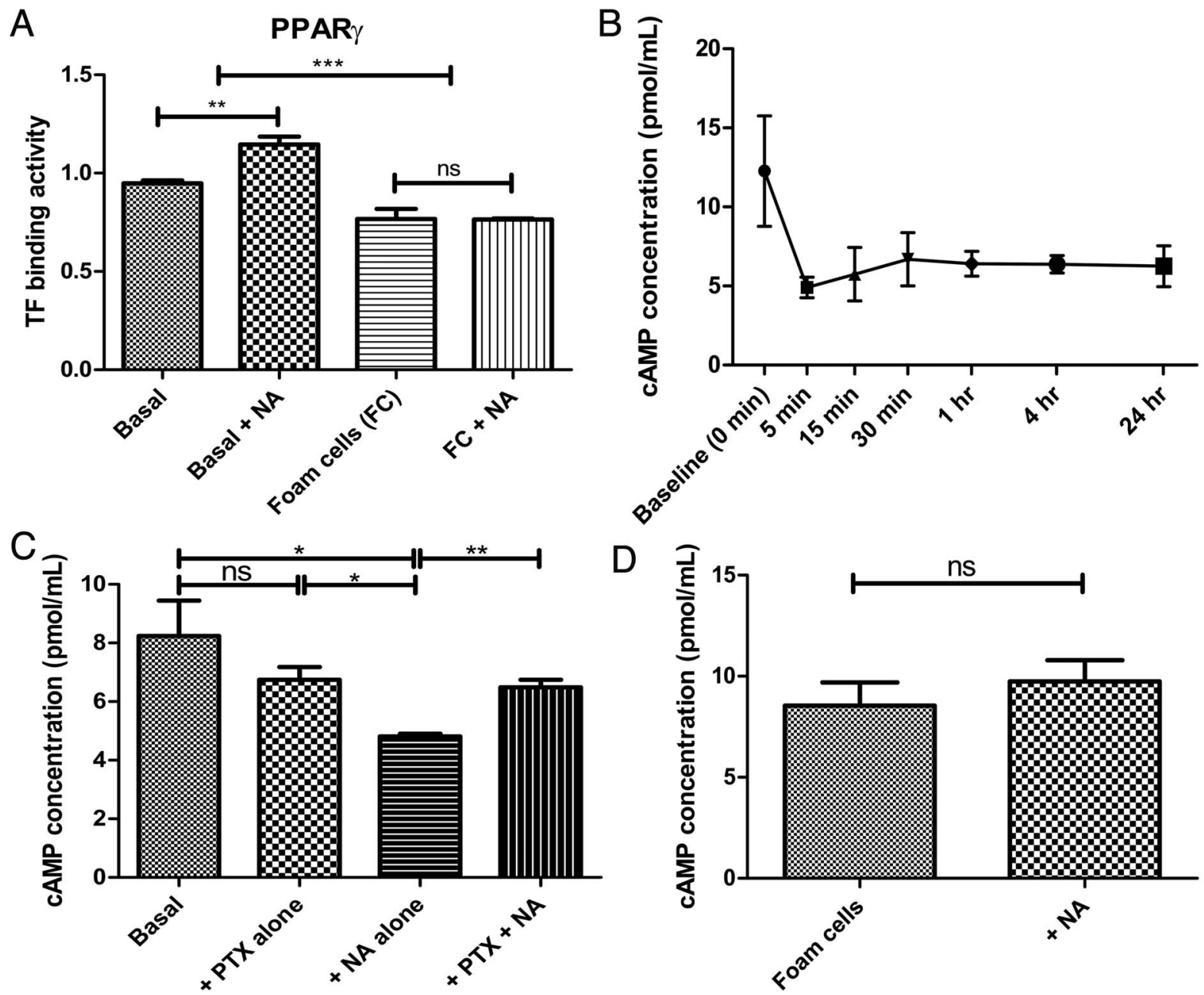

Figure 4. Effects of NA on PPAR $\gamma$ and cAMP pathways in basal versus foam cells. 4A PPARs nuclear binding ELISA showed that cholesterol loading reduced PPAR $\gamma$ transcription factor binding $(n=6$ per group); and that NA significantly increased PPAR $\gamma$ binding in basal macrophages $\left(n=3\right.$ per group) but not in foam cells. 4B NA $\left(1 \times 10^{-4} \mathrm{M}\right)$ rapidly reduced cAMP level and this effect persisted for 24 hours. 4C and 4D Preincubation with pertussis toxin (PTX) or vehicles for 18 hours followed by NA. In basal macrophages, cAMP level diminished in NA alone group compared to control ( $n=3$ per group) and this effect was abolished by PTX pre-incubation. In contrast, NA did not affect cAMP level in foam cells ( $\mathrm{n}=3$ per group). ${ }^{*} \mathrm{P}<0.05,{ }^{* *} \mathrm{P}<0.01, * * * \mathrm{P}<0.001, \mathrm{~ns}=$ non significant. doi:10.1371/journal.pone.0062934.g004

ated protein adipophilin to identify foam cells. Figure 7B showed that GPR109A-positive cells have low content for lipid droplets i.e. are non-foam cell macrophages; whereas Figure 7C demonstrated CD68-positive cells with high lipid-droplets content i.e. "foam cells" macrophages do not co-express GPR109A.

\section{Discussion}

Nicotinic acid drives atherosclerosis regression in humans and acts on monocytes via GPR109A to up-regulate mediators of cholesterol efflux. Recent observations in mice suggest that atherosclerosis progression can be attenuated by nicotinic acid independently of any effect on lipoproteins [25]. These observations suggested that nicotinic acid may exert anti-atherosclerotic effects by directly promoting cholesterol efflux from foam cells. Here, we tested that hypothesis and demonstrated that, while PPAR $\gamma$ agonism enhanced cholesterol efflux, NA failed to do so due to down-regulation of the receptor GPR109A in foam cells as compared with basal macrophages. Using samples obtained at carotid endarterectomy, we demonstrated that a similar phenom- enon occurs in vivo. Our findings imply that direct NA-promotion of cholesterol efflux from foam cells does not contribute to atherosclerosis regression that has been documented with this drug. The patho-physiological relevance of GPR109A expression in monocytes/macrophages and its subsequent down-regulation in foam cells in the context of plaque regression remain to be established.

We studied the effect of NA on peroxisome proliferatoractivated receptors (PPARs), which are members of a nuclear receptor protein family that control transcription cascades in both glucose and lipid metabolism. Both PPAR $\alpha$ and PPAR $\gamma$ are implicated in the regulation of cellular lipid metabolism [31], with PPAR $\gamma$-LXR $\alpha$-ABC transporters pathway being the most studied [28]. Consistent with previous in-vitro studies in non-foam cell macrophage/monocytic cell lines [16,17], we showed that NA has a stimulatory effect on PPAR $\gamma$ expression and nuclear activation with enhanced transcription of one of its downstream effector, CD36; and of the cellular cholesterol efflux ABC transporters. As observed recently in mice by Lukasova et al. [25], we did not detect enhanced transcription with ABCAl with NA, but ABCG1 
A

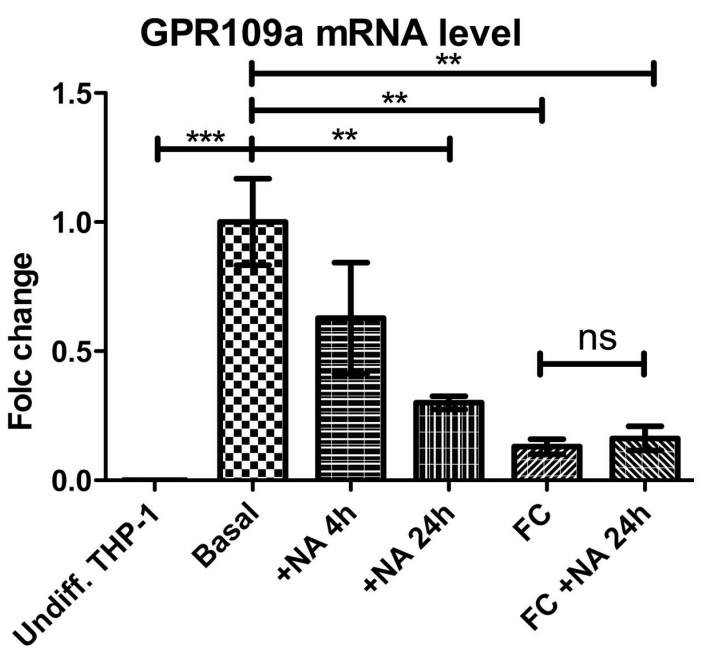

B
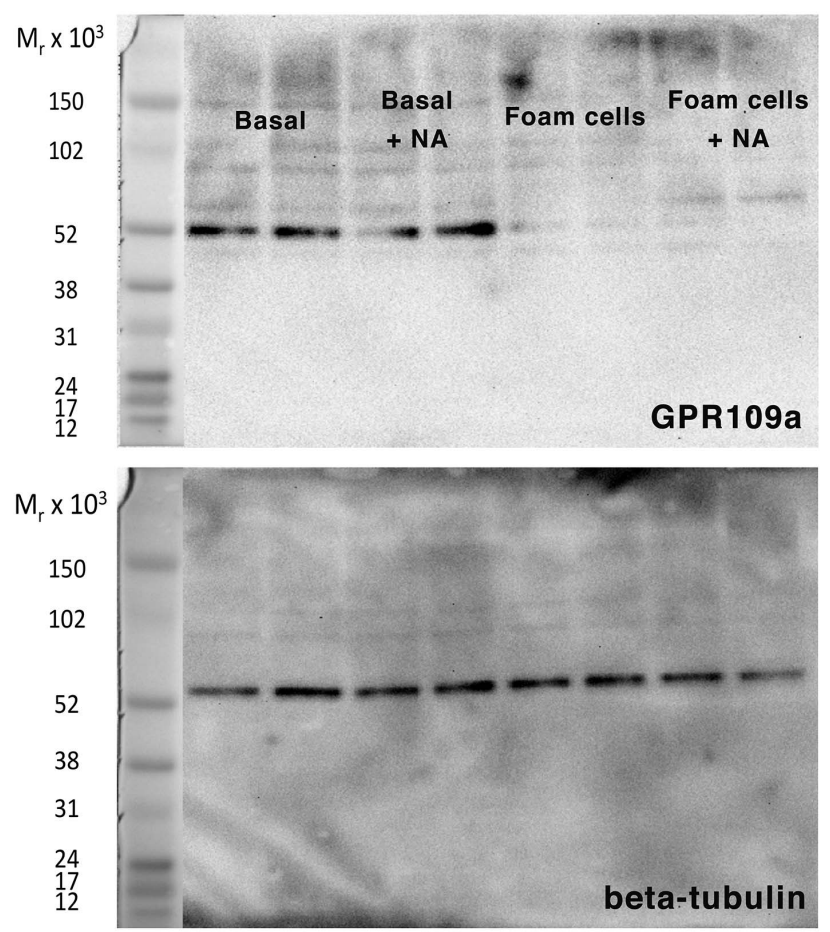

C
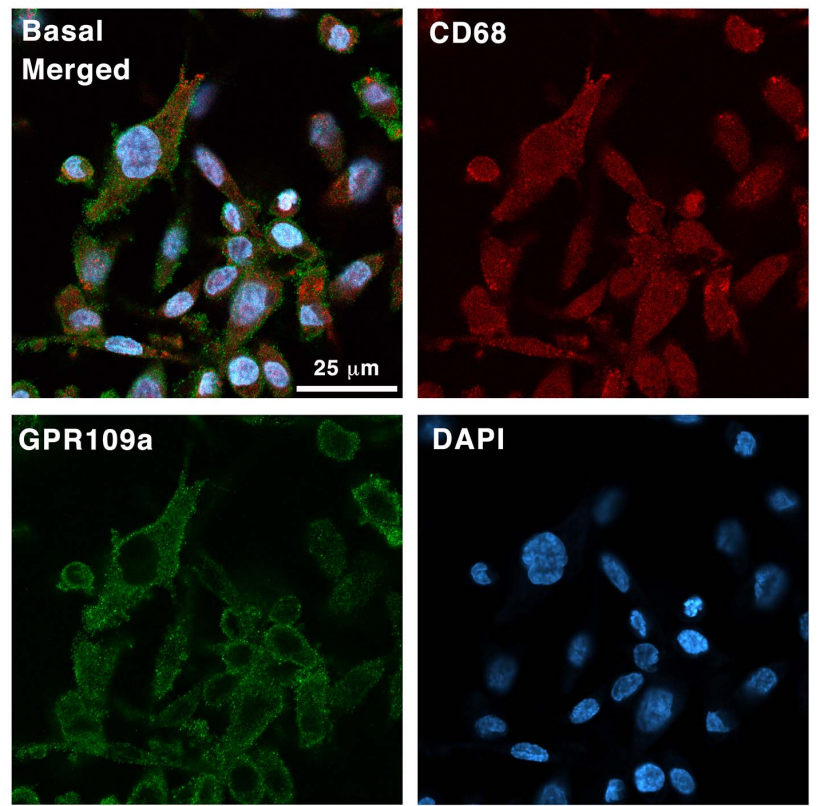

D
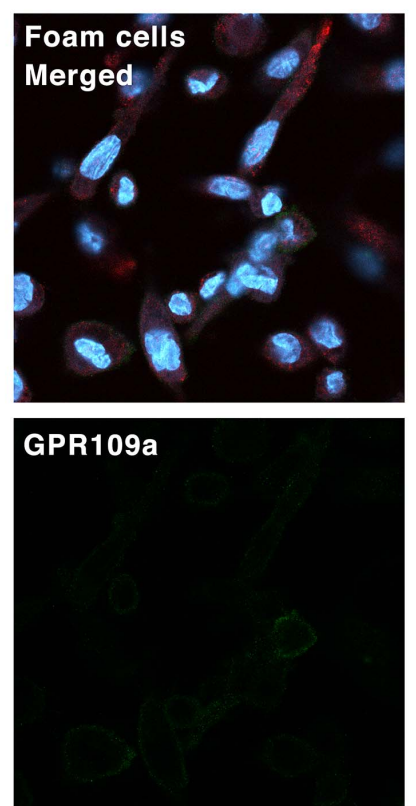
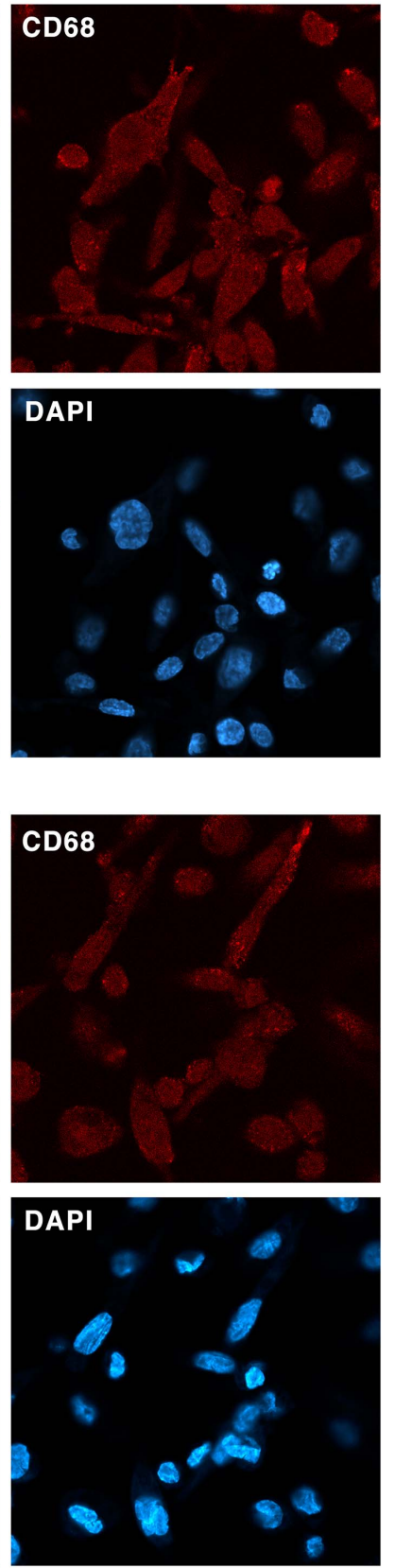

Figure 5. Down-regulation of GPR109A in human macrophage-derived foam cells. 5A GPR109A mRNA was not expressed in undifferentiated THP-1 cells but expression was seen after differentiation into basal macrophages. Treatment with NA for 24 hours caused significant down-regulation of GPR109A mRNA transcription ( $n=3$ per group). Foam cells induction down-regulated GPR109A mRNA transcription compared to basal macrophages ( $n=3$ per group). 5B Western blot showed the loss of protein expression of GPR109A in total cell lysates from foam cells compared to basal macrophages. 5C and 5D Confocal fluorescence immunocytochemistry demonstrated the expression of GPR109A on the cell surface in cultured THP-1 basal macrophages (5C), and the down-regulation of GPR109A expression after foam cell induction (5D).

doi:10.1371/journal.pone.0062934.g005

transcription was significantly up-regulated by NA in basal macrophages. However, we showed that NA loses this stimulatory effect on the RCT apparatus as a result of GPR109A receptor down-regulation after foam cell induction, as well as being unable to affect functionally cellular cholesterol efflux in cultured macrophage-derived foam cells.

NA also suppressed cAMP in non-stimulated, basal monocytic cells, through a mechanism that was pertussis toxin-sensitive, which deactivates $G_{i}$ and $G_{0} G$-proteins. Although this is contrary to Rubic et al [16], who showed a rise in cAMP associated with enhanced cholesterol efflux from basal macrophages by NA, our results are in agreement with several other groups who have observed NA-mediated inhibition of the cAMP response $[32,33]$ and similar effects are also seen in HM74a-transfected CHO-K1 [30], 293EBNA [34], HEK293 and 3T3L1 adipocytes [35], which are at least partially ascribed to inhibition of adenylate cyclase. We demonstrated that this classic cAMP response observed in basal monocytic cells is absent in transformed macrophage-derived foam cells. 


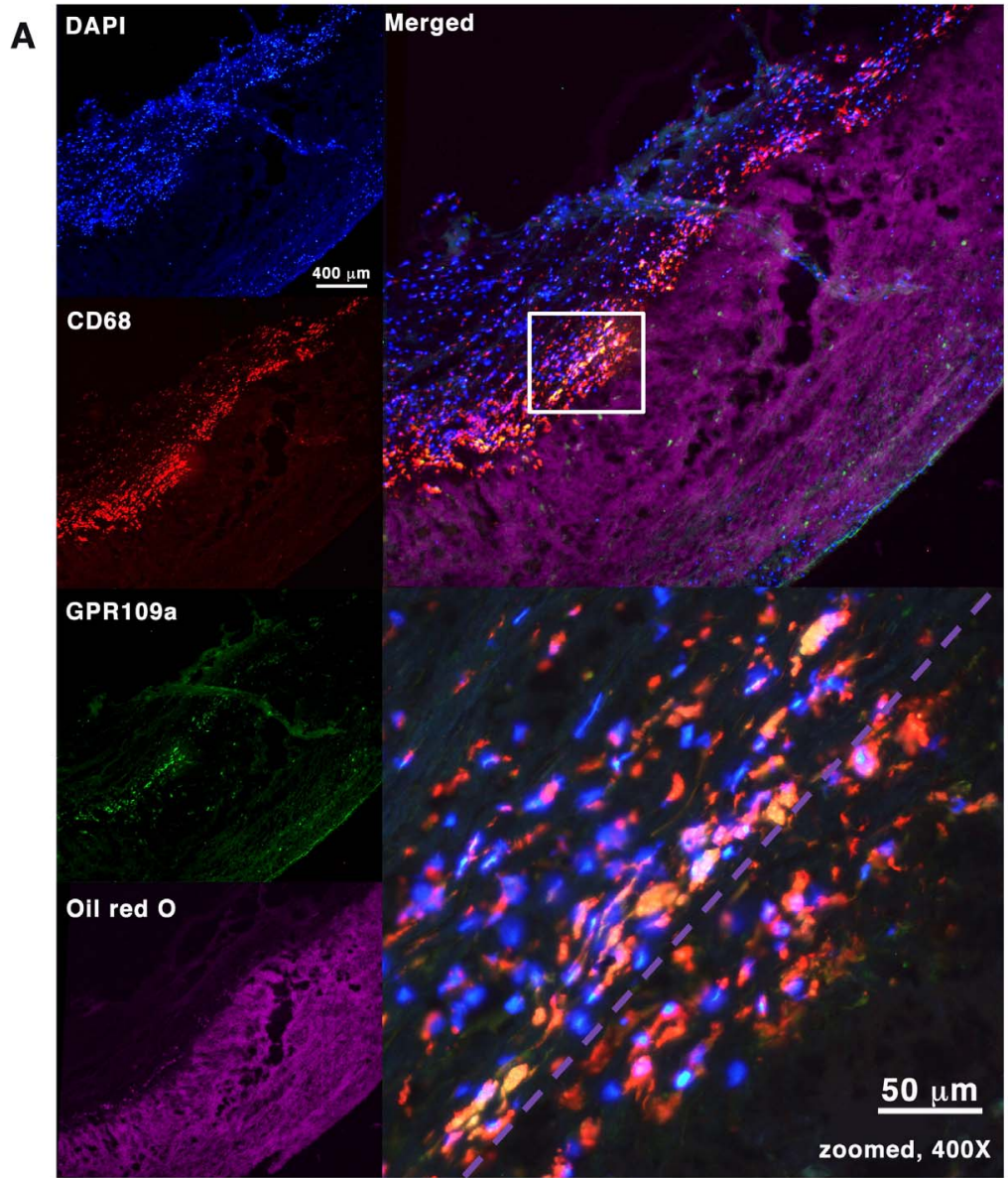

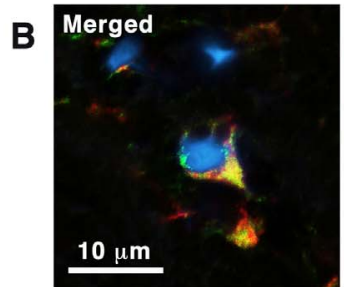
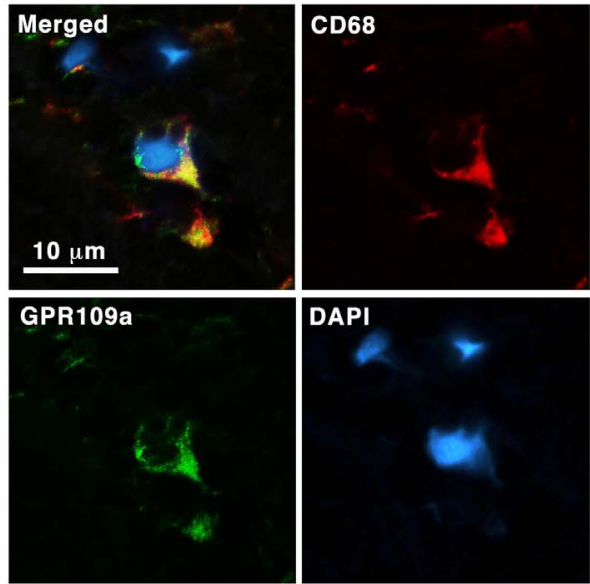

C
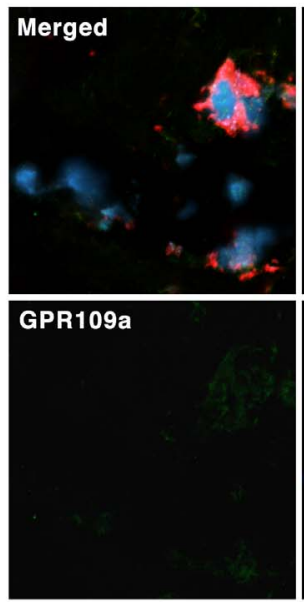

CD68

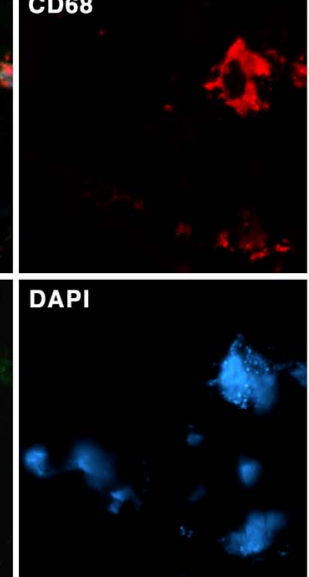

Figure 6. Expression of GPR109A in ex-vivo human carotid plaques. 6A Fluorescence immunohistochemistry staining with antibodies against CD68 and GPR109A. Immediately adjacent $10 \mu \mathrm{m}$ cryosection was stained with Oil Red O for lipid distribution and visualized using Texas Red excitation filter (540-580 nm) in epifluorescence. CD68-positive cells were seen clustering at the interface between lipid-rich region and the overlying fibrous cap. GPR109A co-expression was seen in a sub-population of these CD68-positive cells outside of the lipid-rich region (yellow). Purple dotted line represents the boundary of the lipid-rich region as seen in the image above. 6B and 6C Loss of GPR109A expression in lipid-rich region. Confocal fluorescence images of CD68-positive cells outside of lipid-rich region are shown in $\mathbf{6 B}$; and those within the lipid-rich region, likely to represent foam cells, are shown in $\mathbf{6 C}$.

doi:10.1371/journal.pone.0062934.g006

Our results showed, for the first time, the expression of GPR109A in a subpopulation of CD68-positive plaque macrophages in human carotid plaques. Moreover, these GPR109A and CD68 co-expressing cells appear to cluster just outside of lipid-rich region in plaques at the interface between the lipid pool and the overlying fibrous cap. Our findings are supported by a recent animal study in $\mathrm{LDLR}^{-/-}$mice, which reported co-expression of a red fluorescent protein (RFP) transgene placed under GPR 109A promoter control and a macrophage marker MOMA-2 in murine aortic plaques [25]. These findings provide a plausible target in human plaques for the direct GPR109A-mediated anti-atherosclerotic effects of NA described recently [24] [25]. Adipophilin (perilipin 2) has recently been established as a sensitive marker of monocyte lipid loading [36,37] and that its protein expression is increased in symptomatic carotid atherosclerosis [38]. Using immunofluorescence against adipophilin, we further confirmed that GPR109A expression in symptomatic human carotid plaques is down-regulated in CD68-positive cells that are laden with intracellular lipid-droplets, characteristic of foam cells.

There are limitations in our study, which we have attempted to address. In particular, GPR109A and GPR109B receptors are highly homologous and are $95 \%$ identical on the amino acid level
[39]. The detection of specific GPR109A expression in Western blot and on immunohistochemistry is thus challenging. However, we have recently demonstrated that the anti-GPR109A antibody used in these experiments preferentially targets GPR109A such that its binding on a Western blot was substantially attenuated when GPR109A was specifically knocked down using siRNA [24]. In addition, although GPR 109A and GPR 109B share high degree of homology, only GPR109A binds nicotinic acid with high affinity. In our cholesterol efflux study, we chose not to evaluate free cholesterol and esterified cholesterol (EC) separately, since early study has estimated that up to $30 \%$ of the cellular EC pool in THP-1 foam cells was derived directly from un-degraded AcLDLderived EC, hence bypassing the normal hydrolysis/re-esterification cycle [40]. Therefore, attempts to separately evaluate free cholesterol and EC would be confounded and would make a valid interpretation difficult. In addition, one interesting observation from our RCT gene expression experiment also remained unexplained. After the initial up-regulation following Ac-LDL incubation, both PPAR $\gamma$ and its heterodimerisation partner $\operatorname{LXR} \alpha$ mRNA transcription appeared to be down-regulated (beyond baseline) in the resting phase (Figure 3A). Although we found no clear explanation from the literature, we were reassured by our 

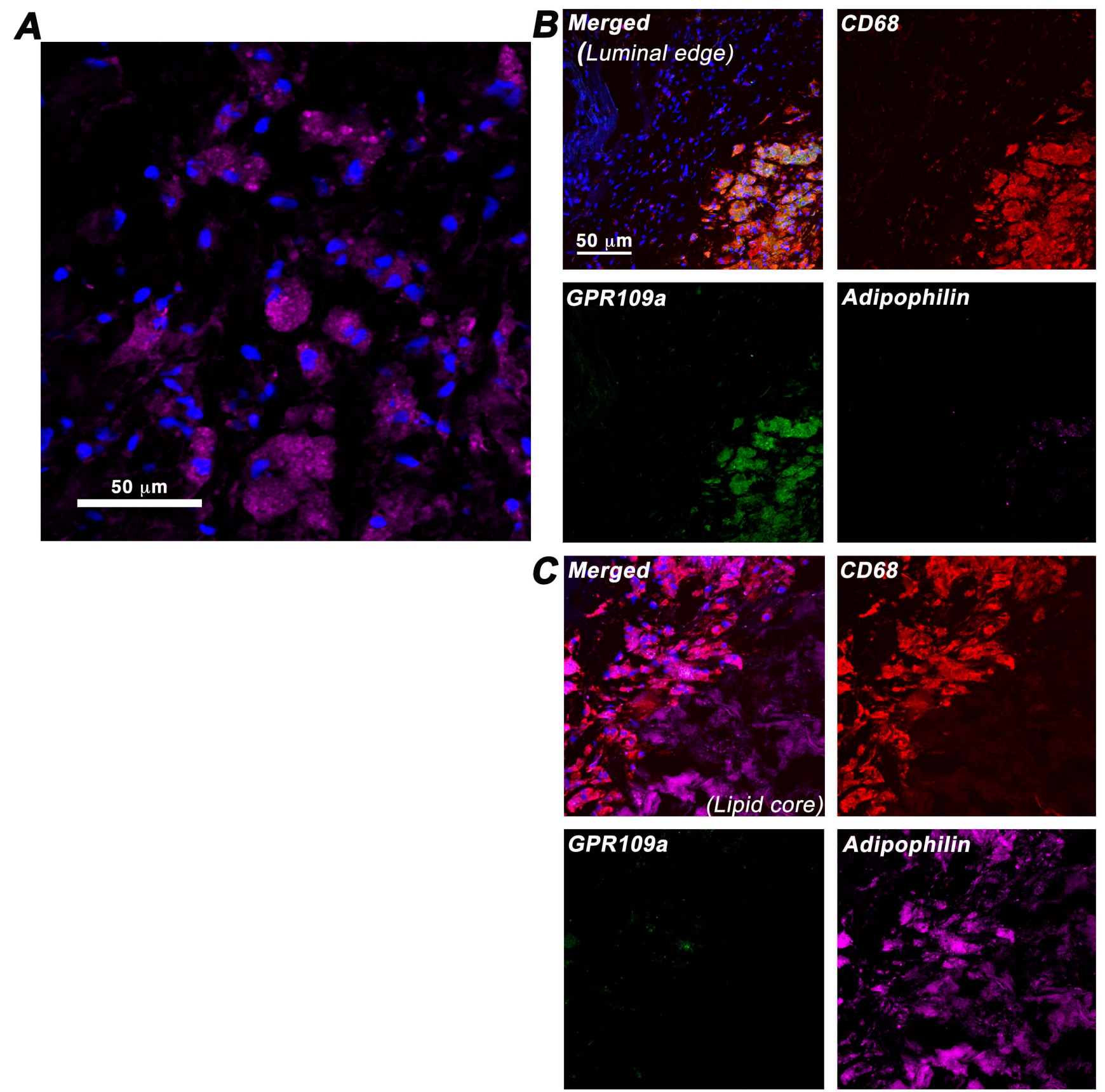

Figure 7. Down-regulation of GPR109A in ex-vivo lipid-laiden plaque foam cells. Adipophilin (perilipin 2) staining is specific to intracellular lipid-droplet associated protein and represents a sensitive marker of foam cells. 7A High-powered confocal image showed the outline of intra-cellular lipid droplets. 7B GPR109A is strongly co-expressed in CD68-positive plaque macrophages without extensive lipid-loading i.e. non-foam cells; whereas plaque foam cells, which showed strong co-expression of CD68 and adipophilin due to extensive lipid-loading as shown in 7C, do not co-express GPR109A.

doi:10.1371/journal.pone.0062934.g007

subsequent complete PPAR $\alpha, \gamma, \delta$ transcription factor binding ELISA assay, which also demonstrated a down-regulation of PPAR $\gamma$ transcription factor activity following the same foam cell induction protocol (Figure 4A). Peculiarly, PPAR $\alpha$ transcription factor activity was enhanced by the same foam cell treatment. Therefore, although the PPAR regulatory mechanisms remain illusive, our foam cell induction protocol, with its resting phase, produced viable foam cells that displayed diverse PPAR responses. Moreover, stimulation of induced foam cells with GW1929 elicited the anticipated effect of LXR $\alpha$ and ABCG1 mRNA transcription up-regulation (Figure 3B, right column), further supporting that the induced foam cells behaved appropriately. The transcriptional regulation of nuclear factor $\operatorname{PPAR} \alpha, \gamma$, and $\delta$ is complex [41,42] and beyond of scope of our current study. The authors would like to postulate that Ac-LDL, being itself a pro-inflammatory stimulus, may stimulate the release of pro-inflammatory cytokine such as TNF- $\alpha$ and IL-1 $\beta$, which is known to down-regulate PPAR $\gamma$ mRNA transcription $[43,44]$. During the resting phase, when the 
overwhelming lipid loading stimulus was withdrawn, the proinflammatory after-effect might have contributed to the "overshot" phenomenon as seen with PPAR $\gamma$ mRNA transcription and that of its partner LXR $\alpha$.

Besides its potential pharmacological value, there remain important biological questions as to the physiological role of GPR109A, for which the cognate ligand is believed to be $\beta$ hydroxybutyrate [45]. $\beta$-hydroxybutyrate is a ketone body that is produced from acetyl-CoA in hepatocytes and is an alternative energy source to the brain and, to a lesser extent, the heart when glucose availability is low during fasting or starvation. Activation of GPR 109A in adipocytes inhibits fatty acid release, possibly acting as a negative feedback against excessive lipolysis in starvation [46]. Indeed plasma concentration of ketones can change over several orders of magnitude under normal physiology [21]. However, the physiological function of GPR109A in immune cells is still largely unknown. Activation of GPR109A by the bacterial fermentation product, butyrate, has been shown to exert tumour-suppressing effects in colon cancer [47]; while in cerebral hypoxia, $\beta$ hydroxybutyrate is shown to be neuroprotective [48-50]. Although this may reflect adaptations to metabolic substrate utilisation/energetics, immune cell modulation via GPR109A is another plausible explanation.

The co-expression of GPR109A in CD68-positive immune cells in human plaques at the interface between lipid pool and the overlying fibrous cap may suggest a regulatory cross-talk between 'metabolic' and 'inflammatory' pathways, which is increasingly appreciated [51]. We have previously shown anti-inflammatory effects of NA in both adipocytes [23] and stimulated monocytes [24], those being the two principal cell types bearing GPR109A. Each of these cell types is implicated in inflammatory pathologies relating to obesity and/or high caloric intake. It is therefore plausible that a metabolic mediator that is regulated and released by the liver over a large dynamic range in starvation might be involved in the suppression of inflammation in these cell types. Although no direct measurement of $\beta$-hydroxybutyrate has been made in atherosclerotic plaque, the selective expression of GPR109A in macrophages suggests that it, or an alternative ligand, may have a role in immunomodulation in that context.

Finally, it is important to allude to the potential mechanisms of GPR109A down-regulation in foam cells. As with most G-protein coupled signaling, GPR 109A is negatively regulated upon receptor stimulation. Ligand binding of GPR109A causes activation of Gprotein coupled receptor kinases (GRKs), which in turn phosphorylate the occupied receptor [52]. The phosphorylated GPR109A is then susceptible to binding of regulatory adaptor protein $\beta$-arrestins. In addition to direct attenuation of GPCRsignalling (desensitization), binding of $\beta$-arrestins also recruits AP2 and clathrin to facilitate endocytosis via clathrin-coated pits and recycling of desensitized GPCR [53]. Moreover, it has recently been shown that $\beta$-arrestins contribute to the $\mathrm{PGD}_{2}$-mediated cutaneous flushing associated with NA [54], and antagonize NF$\kappa \mathrm{B}$ signaling [55], both independent of the classic G-protein

\section{References}

1. Altschul R, Hoffer A, Stephen JD (1955) Influence of nicotinic acid on serum cholesterol in man. Arch Biochem Biophys 54: 558-559.

2. Villines TC, Kim AS, Gore RS, Taylor AJ (2011) Niacin: The Evidence, Clinical Use, and Future Directions. Current Atherosclerosis Reports 14: 49-59.

3. Canner PL, Berge KG, Wenger NK, Stamler J, Friedman L, et al. (1986) Fifteen year mortality in Coronary Drug Project patients: long-term benefit with niacin. J Am Coll Cardiol 8: 1245-1255.

4. Bruckert E, Labreuche J, Amarenco P (2010) Meta-analysis of the effect of nicotinic acid alone or in combination on cardiovascular events and atherosclerosis. Atherosclerosis 210: 353-361. signaling. As a result, although little is currently known with regards to $\beta$-arrestin signaling in foam cells, its involvement in $\mathrm{G}$ protein coupled receptor down-regulation, and its direct involvement in downstream cell signaling, make $\beta$-arrestins an attractive target for future investigation.

\section{Conclusions}

In conclusion, this study shows that despite its potent antiinflammatory effect on human macrophages, nicotinic acid has no direct effect on reverse cholesterol transport in macrophagederived foam cells; and this may be explained by the downregulation of its receptor GPR109A upon foam cell transformation. This implies that direct NA-promotion of cholesterol efflux from foam cells does not contribute to atherosclerosis regression, which has been demonstrated with this drug. Given the cellular distribution of GPR109A/CD68 co-expressing macrophages in human carotid plaques, the patho-physiological significance of GPR109A expression in human plaque macrophages and its down regulation in foam cells remains to be elucidated.

\section{Supporting Information}

Figure S1 Diagrammatic representation of cell treatment in cholesterol loading and efflux experiments. All treatment groups had identical exposure to PMA and identical culture duration. Cell treatments were identical in qRT-PCR, cholesterol efflux, Western blot (WB), and immunofluorescence (IF) staining experiments; in qRT-PCR experiments, treatment with NA and GW1929 were applied at the end (at asterisk *) in line with foam cells $(\mathrm{FC})$ group to ensure robust comparison.

(TIF)

Figure S2 Effect of NA on foam cells at different concentration and at different time points. Cholesterol efflux was studied by measurement extracted cholesterol content after hexane:isopropanol extraction. Nicotinic acid (NA) has no effect on cholesterol efflux compared to using HDL alone at 4 hours $(\mathbf{S 2 A})$ and at 48 hours $(\mathbf{S 2 B})$. Data at 24 hours is shown in main Figure 2. NA concentration: NA-3 $=1 \times 10^{-3} \mathrm{M}$, NA$4=1 \times 10^{-4} \mathrm{M}, \mathrm{NA}-5=1 \times 10^{-5-} \mathrm{M}, \mathrm{NA}-6=1 \times 10^{-6} \mathrm{M}$. Time indicated duration of NA treatment.

(TIF)

\section{Acknowledgments}

The authors would like to thank the skillful laboratory management by Phil Townsend.

\section{Author Contributions}

Conceived and designed the experiments: JTC JED RPG. Performed the experiments: JTC JED NR AJ. Analyzed the data: JTC JED AH RPC. Contributed reagents/materials/analysis tools: AH. Wrote the paper: JTC RPC.

5. Lavigne PM, Karas R (2012) The Role of Niacin in the Aftermath of Aim-High: A Meta-Analysis. Journal of the American College of Cardiology 59: E1687.

6. Cashin-Hemphill L, Mack WJ, Pogoda JM, Sanmarco ME, Azen SP, et al. (1990) Beneficial effects of colestipol-niacin on coronary atherosclerosis. A 4-year follow-up. JAMA 264: 3013-3017.

7. Brown BG, Zhao XQ, Chait A, Fisher LD, Cheung MC, et al. (2001) Simvastatin and niacin, antioxidant vitamins, or the combination for the prevention of coronary disease. N Engl J Med 345: 1583-1592.

8. Villines TC, Stanek EJ, Devine PJ, Turco M, Miller M, et al. (2010) The ARBITER 6-HALTS Trial (Arterial Biology for the Investigation of the Treatment Effects of Reducing Cholesterol 6-HDL and LDL Treatment 
Strategies in Atherosclerosis): final results and the impact of medication adherence, dose, and treatment duration. J Am Coll Cardiol 55: 2721-2726.

9. Taylor AJ, Sullenberger LE, Lee HJ, Lee JK, Grace KA (2004) Arterial Biology for the Investigation of the Treatment Effects of Reducing Cholesterol (ARBITER) 2: a double-blind, placebo-controlled study of extended-release niacin on atherosclerosis progression in secondary prevention patients treated with statins. Circulation 110: 3512-3517.

10. Taylor AJ, Lee HJ, Sullenberger LE (2006) The effect of 24 months of combination statin and extended-release niacin on carotid intima-media thickness: ARBITER 3. Curr Med Res Opin 22: 2243-2250.

11. Taylor AJ, Villines TC, Stanek EJ, Devine PJ, Griffen L, et al. (2009) Extendedrelease niacin or ezetimibe and carotid intima-media thickness. N Engl J Med 361: 2113-2122.

12. Lee JMS, Robson MD, Yu L-M, Shirodaria CC, Cunnington G, et al. (2009) Effects of High-Dose Modified-Release Nicotinic Acid on Atherosclerosis and Vascular FunctionA Randomized, Placebo-Controlled, Magnetic Resonance Imaging Study. Journal of the American College of Cardiology 54: 1787-1794.

13. Boden WE, Probstfield JL, Anderson T, Chaitman BR, Desvignes-Nickens P, et al. (2011) Niacin in patients with low HDL cholesterol levels receiving intensive statin therapy. N Engl J Med 365: 2255-2267.

14. Merck News Release "Merck announces HPS2-THRIVE study of TREDAPTIVE (Extended release niacin/laropiprant) did not achieve primary endpoint" released 20th December 2012.

15. Wu Z-H, Zhao S-P (2009) Niacin Promotes Cholesterol Efflux through Stimulation of the PPAR $\gamma$-LXR $\alpha$-ABCA1 Pathway in 3T3-L1 Adipocytes. Pharmacology 84: 282-287.

16. Rubic T, Trottmann M, Lorenz RL (2004) Stimulation of CD36 and the key effector of reverse cholesterol transport ATP-binding cassette A1 in monocytoid cells by niacin. Biochemical Pharmacology 67: 411-419.

17. Knowles H, Poole R, Workman P, Harris A (2006) Niacin induces PPAR $\gamma$ expression and transcriptional activation in macrophages via HM74 and HM74a-mediated induction of prostaglandin synthesis pathways. Biochemical Pharmacology 71: 646-656.

18. Ozasa H, Ayaori M, Iizuka M, Terao Y, Uto-Kondo H, et al. (2011) Pioglitazone enhances cholesterol efflux from macrophages by increasing ABCA1/ABCG1 expressions via PPAR $\gamma / \mathrm{LXR} \alpha$ pathway: Findings from in vitro and ex vivo studies. Atherosclerosis 219: 141-150.

19. Llodra J, Angeli V, Liu J, Trogan E, Fisher EA, et al. (2004) Emigration of monocyte-derived cells from atherosclerotic lesions characterizes regressive, but not progressive, plaques. Proc Natl Acad Sci U S A 101: 11779-11784.

20. Feig JE, Parathath S, Rong JX, Mick SL, Vengrenyuk Y, et al. (2011) Reversal of Hyperlipidemia With a Genetic Switch Favorably Affects the Content and Inflammatory State of Macrophages in Atherosclerotic Plaques. Circulation 123: 989-998.

21. Offermanns S (2006) The nicotinic acid receptor GPR109A (HM74A or PUMA-G) as a new therapeutic target. Trends in Pharmacological Sciences 27: 384-390.

22. Digby JE, Ruparelia N, Choudhury RP (2012) Niacin in Cardiovascular Disease: Recent Preclinical and Clinical Developments. Arteriosclerosis, Thrombosis, and Vascular Biology 32: 582-588.

23. Digby JE, McNeill E, Dyar OJ, Lam V, Greaves DR, et al. (2010) Antiinflammatory effects of nicotinic acid in adipocytes demonstrated by suppression of fractalkine, RANTES, and MCP-1 and upregulation of adiponectin. Atherosclerosis 209: 89-95.

24. Digby JE, Martinez F, Jefferson A, Ruparelia N, Chai JT, et al. (2012) AntiInflammatory Effects of Nicotinic Acid in Human Monocytes Are Mediated by GPR109A Dependent Mechanisms. Arterioscler Thromb Vasc Biol 32: 669 676.

25. Lukasova M, Malaval C, Gille A, Kero J, Offermanns S (2011) Nicotinic acid inhibits progression of atherosclerosis in mice through its receptor GPR109A expressed by immune cells. Journal of Clinical Investigation 121: 1163-1173.

26. Robinet P, Wang Z, Hazen SL, Smith JD (2010) A simple and sensitive enzymatic method for cholesterol quantification in macrophages and foam cells. The Journal of Lipid Research 51: 3364-3369.

27. Pfaffl M (2001) A new mathematical model for relative quantification in realtime RT-PCR. Nucleic acids research 29: 2002-2007.

28. Chawla A, Boisvert WA, Lee C-H, Laffitte BA, Barak Y, et al. (2001) A PPARgLXR-ABCA1 pathway in macrophages in involved in cholesterol efflux and atherogenesis. Molecular Cell 7: 161-171.

29. Oram JF, Heinecke JW (2005) ATP-binding Cassette Transporter A1: A Cell Cholesterol Exporter That Protects Against Cardiovasculra Disease. Physiol Rev 85: $1343-1372$.

30. Tunaru S, Kero J, Schaub A, Wufka C, Blaukat A, et al. (2003) PUMA-G and HM74 are receptors for nicotinic acid and mediate its anti-lipolytic effect. Nat Med 9: 352-355.
31. Chinetti G, Lestavel S, Bocher V, Remaley AT, Neve B, et al. (2001) PPAR$\alpha$ and PPAR- $\gamma$ activators induce cholesterol removal from human macrophage foam cells through stimulation of the ABCAl pathway. Nature Medicine 7: 5358.

32. Lacasa D, Agli B, Giudicelli Y (1986) Increased sensitivity of fat cell adenylate cyclase to stimulatory agonists during fasting is not related to impaired inhibitory coupling system. FEBS Lett 202: 260-266.

33. Fatemi SH (1986) Evaluation of the effects of forskolin and the antilipolytic agents insulin and nicotinic acid on cyclic AMP levels in rat epididymal adipocytes. Biomed Biochim Acta 45: 539-547.

34. Soga T, Kamohara M, Takasaki J, Matsumoto S, Saito T, et al. (2003) Molecular identification of nicotinic acid receptor. Biochem Biophys Res Commun 303: 364-369.

35. Zhang Y, Schmidt RJ, Foxworthy P, Emkey R, Oler JK, et al. (2005) Niacin mediates lipolysis in adipose tissue through its $\mathrm{G}$-protein coupled receptor HM74A. Biochem Biophys Res Commun 334: 729-732.

36. Buechler C, Ritter M, Duong CO Orso E, Kapinsky M, et al. (2001) Adipophilin is a sensitive marker for lipid loading in human blood monocytes. Biochimica et Biophysica Acta (BBA) 1532: 97-104.

37. Wang X, Reape TJ, Li X, Rayner K, Webb CL, et al. (1999) Induced expression of adipophilin mRNA in human macrophages stimulated wit oxidised lowdensitiy lipoprotein and in atherosclerotic lesions. FEBS Lett 462: 145-150.

38. Nuotio K, Isoviita PM, Saksi J, Ijas P, Pitkaniemi J, et al. (2007) Adipophilin Expression Is Increased in Symptomatic Carotid Atherosclerosis: Correlation With Red Blood Cells and Cholesterol Crystals *Online Data. Stroke 38: 17911798

39. Offermanns S, Colletti SL, Lovenberg TW, Semple G, Wise A, et al. (2011) International Union of Basic and Clinical Pharmacology. LXXXII: Nomenclature and Classification of Hydroxy-carboxylic Acid Receptors (GPR81, GPR109A, and GPR109B). Pharmacological Reviews 63: 269-290.

40. Kritharides L, Christian A, Stoudt G, Morel CR, Rothblat GH (1998) Cholesterol metabolism and efflux in human THP-1 macrophages. Arterioscler Thromb Vasc Biol 18: 1589-1599.

41. Plutzky J (2011) The PPAR-RXR Transcriptional Complex in the Vasculature: Energy in the Balance. Circulation Research 108: 1002-1016.

42. Rosenson RS, Wright RS, Farkouh M, Plutzky J (2012) Modulating peroxisome proliferator-activated receptors for therapeutic benefit? Biology, clinical experience, and future prospects. American Heart Journal 164: 672-680.

43. Ye J (2008) Regulation of PPARgamma function by TNF-alpha. Biochem Biophys Res Commun 374: 405-408.

44. Kajita K, Mune T, Kanoh Y, Natsume Y, Ishizawa M, et al. (2004) TNFalpha reduces the expression of peroxisome proliferator-activated receptor gamma (PPARgamma) via the production of ceramide and activation of atypical PKC. Diabetes Res Clin Pract 66 Suppl 1: S79-83.

45. Taggart AK, Kero J, Gan X, Cai TQ Cheng K, et al. (2005) (D)-betaHydroxybutyrate inhibits adipocyte lipolysis via the nicotinic acid receptor PUMA-G. J Biol Chem 280: 26649-26652.

46. Senior B, Loridan L (1968) Direct regulatory effect of ketones on lipolysis and on glucose concentrations in man. Nature 219: 83-84.

47. Thangaraju M, Cresci GA, Liu K, Ananth S, Gnanaprakasam JP, et al. (2009) GPR 109A Is a G-protein-Coupled Receptor for the Bacterial Fermentation Product Butyrate and Functions as a Tumor Suppressor in Colon. Cancer Research 69: 2826-2832.

48. Masuda R, Monahan JW, Kashiwaya Y (2005) D-beta-hydroxybutyrate is neuroprotective against hypoxia in serum-free hippocampal primary cultures. J Neurosci Res 80: 501-509.

49. Prins ML, Lee SM, Fujima LS, Hovda DA (2004) Increased cerebral uptake and oxidation of exogenous betaHB improves ATP following traumatic brain injury in adult rats. J Neurochem 90: 666-672.

50. Samoilova M, Weisspapir M, Abdelmalik P, Velumian AA, Carlen PL (2010) Chronic in vitro ketosis is neuroprotective but not anti-convulsant. J Neurochem 113: 826-835.

51. Osborn O, Olefsky JM (2012) The cellular and signaling networks linking the immune system and metabolism in disease. Nat Med 18: 363-374.

52. Ma L, Pei G (2007) beta-arrestin signaling and regulation of transcription. Journal of Cell Science 120: 213-218.

53. Lin FT, Krueger KM, Kendall HE, Daaka Y, Fredericks ZL, et al. (1997) Clathrin-mediated endocytosis of the beta-adrenergic receptor is regulated by phosphorylation/dephosphorylation of beta-arrestin1. J Biol Chem 272: 3105131057.

54. Walters RW, Shukla AK, Kovacs JJ, Violin JD, DeWire SM, et al. (2009) $\beta$ Arrestin 1 mediates nicotinic acid-induced flushing, but not its antilipolytic effect, in mice. Journal of Clinical Investigation 119: 1312-1321.

55. Witherow DS (2004) $\beta$-Arrestin inhibits NF- B activity by means of its interaction with the NF- B inhibitor I B Proceedings of the National Academy of Sciences 101: 8603-8607. 